BNL-102284-2013-IR

\title{
Planning Document for an NBSR Conversion Safety Analysis Report
}

\author{
D.J. Diamond, J.S. Baek, A.L. Hanson, \\ L-Y. Cheng, N. Brown, and A. Cuadra
}

September, 2013

\begin{abstract}
Nuclear Science and Technology Department
Brookhaven National Laboratory
\end{abstract}

\section{U.S. Department of Energy \\ National Institute of Standards and Technology}

Notice: This manuscript has been authored by employees of Brookhaven Science Associates, LLC under Contract No. DE-AC02-98CH10886 with the U.S. Department of Energy. The publisher by accepting the manuscript for publication acknowledges that the United States Government retains a non-exclusive, paid-up, irrevocable, world-wide license to publish or reproduce the published form of this manuscript, or allow others to do so, for United States Government purposes. 


\section{DISCLAIMER}

This report was prepared as an account of work sponsored by an agency of the United States Government. Neither the United States Government nor any agency thereof, nor any of their employees, nor any of their contractors, subcontractors, or their employees, makes any warranty, express or implied, or assumes any legal liability or responsibility for the accuracy, completeness, or any third party's use or the results of such use of any information, apparatus, product, or process disclosed, or represents that its use would not infringe privately owned rights. Reference herein to any specific commercial product, process, or service by trade name, trademark, manufacturer, or otherwise, does not necessarily constitute or imply its endorsement, recommendation, or favoring by the United States Government or any agency thereof or its contractors or subcontractors. The views and opinions of authors expressed herein do not necessarily state or reflect those of the United States Government or any agency thereof. 
BNL-102284-2013-IR

\section{Planning Document for an NBSR}

\section{Conversion Safety Analysis Report}

Manuscript Completed:

September 25, 2013

Prepared by:

D.J. Diamond, J.S. Baek, A.L. Hanson, L-Y. Cheng, N. Brown, and A. Cuadra

Nuclear Science \& Technology Department

Brookhaven National Laboratory

Upton, NY 11973

Prepared for:

National Nuclear Security Administration

National Institute of Standards and Technology 



\begin{abstract}
The NIST Center for Neutron Research (NCNR) is a reactor-laboratory complex providing the National Institute of Standards and Technology (NIST) and the nation with a world-class facility for the performance of neutron-based research. The heart of this facility is the National Bureau of Standards Reactor (NBSR). The NBSR is a heavy water moderated and cooled reactor operating at $20 \mathrm{MW}$. It is fueled with high-enriched uranium (HEU) fuel elements. A Global Threat Reduction Initiative (GTRI) program is underway to convert the reactor to low-enriched uranium (LEU) fuel. This program includes the qualification of the proposed fuel, uranium and molybdenum alloy foil clad in an aluminum alloy, and the development of the fabrication techniques. This report is a planning document for the conversion Safety Analysis Report (SAR) that would be submitted to, and approved by, the Nuclear Regulatory Commission (NRC) before the reactor could be converted.

This report follows the recommended format and content from the NRC codified in NUREG1537, "Guidelines for Preparing and Reviewing Applications for the Licensing of Non-power Reactors,” Chapter 18, "Highly Enriched to Low-Enriched Uranium Conversions.” The emphasis herein is on the SAR chapters that require significant changes as a result of conversion, primarily Chapter 4, Reactor Description, and Chapter 13, Safety Analysis. The document provides information on the proposed design for the LEU fuel elements and identifies what information is still missing. This document is intended to assist ongoing fuel development efforts, and to provide a platform for the development of the final conversion SAR. This report contributes directly to the reactor conversion pillar of the GTRI program, but also acts as a boundary condition for the fuel development and fuel fabrication pillars.
\end{abstract}




\section{TABLE OF CONTENTS}

1. GENERAL DESCRIPTION OF THE FACILITY …….................................................... 1

1.1 Summary Description of Changes............................................................................... 1

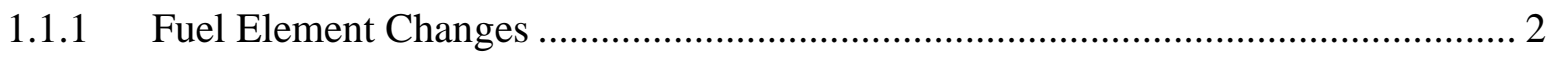

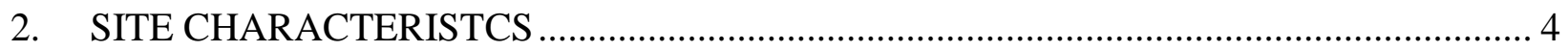

3. DESIGN OF STRUCTURES, SUYSTEMS, AND COMPONENTS ................................... 4

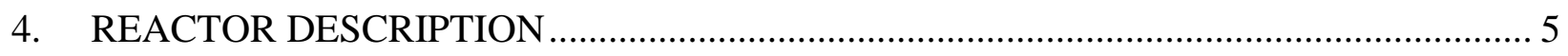

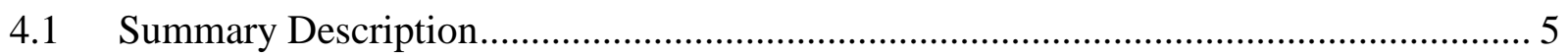

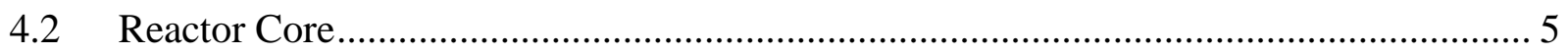

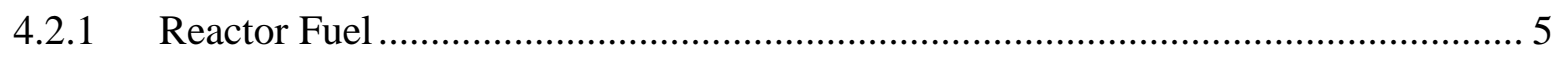

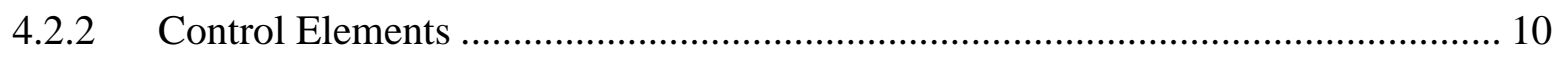

4.2.3 Neutron Moderator and Reflector ................................................................ 11

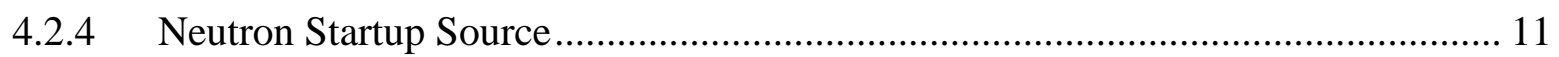

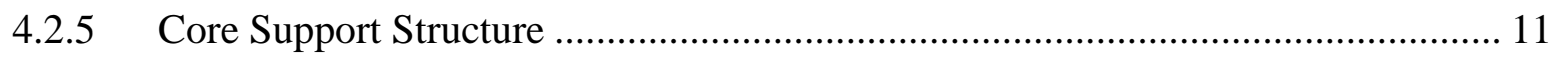

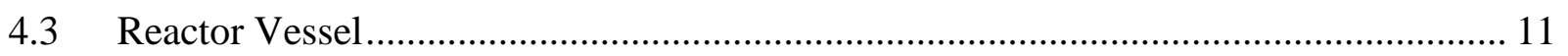

$4.4 \quad$ Biological Shield ........................................................................................... 11

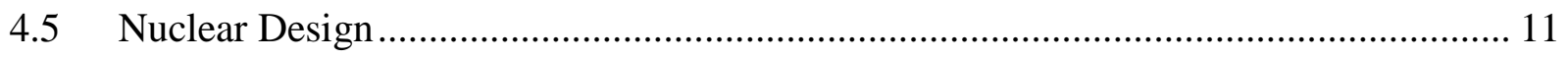

4.5.1 Neutronic and Burn-up Model of the NBSR ...................................................... 13

4.5.2 Reactivity Calculations ................................................................................ 13

4.5.3 Power Distribution and Energy Spectra Calculations............................................. 15

4.5.4 Reactor Kinetics Parameters ............................................................................. 16

4.5.5 Technical Specifications ................................................................................ 16

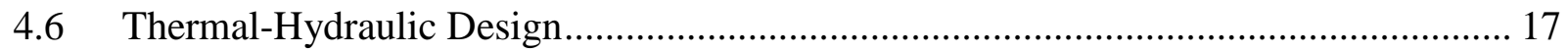

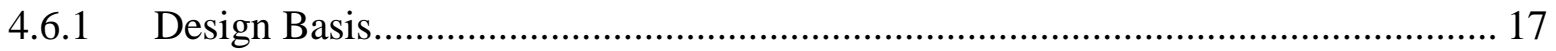

4.6.2 Determination of Limiting Conditions.................................................................. 18

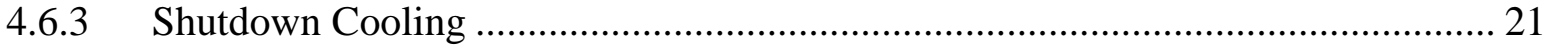

4.6.4 Operation with Natural Convection .................................................................. 21

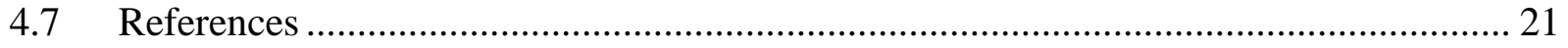

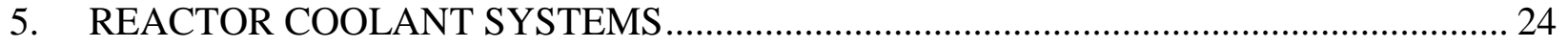

6. ENGINEERED SAFETY FEATURES ....................................................................... 24

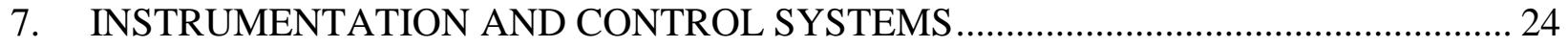

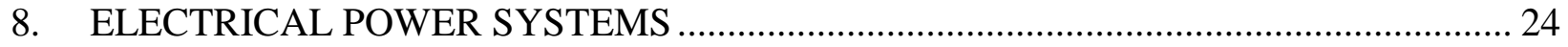

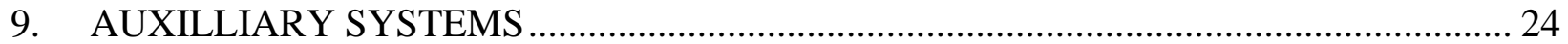


10. EXPERIMENTAL FACILITIES AND UTILIZATION................................................. 24

11. RADIATION PROTECTION AND RADIOACTIVE WASTE ....................................... 24

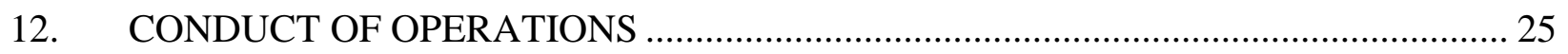

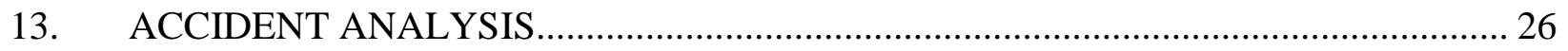

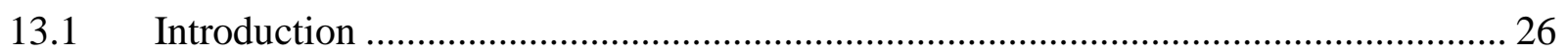

13.2 Maximum Hypothetical Accident ......................................................................... 26

13.3 Accidents Due to Insertion of Excess Reactivity ………………............................. 27

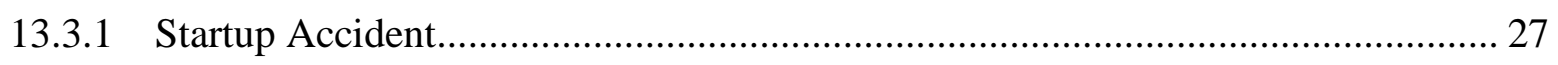

13.3.2 Maximum Reactivity Insertion Accident .............................................................. 27

13.3.3 Other Reactivity Insertion Events .................................................................... 27

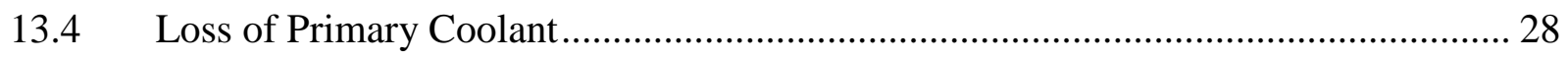

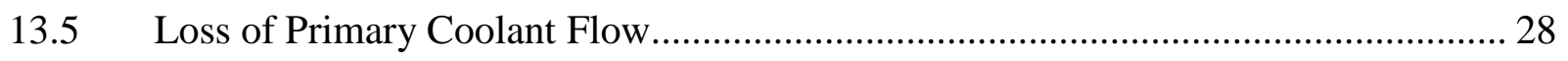

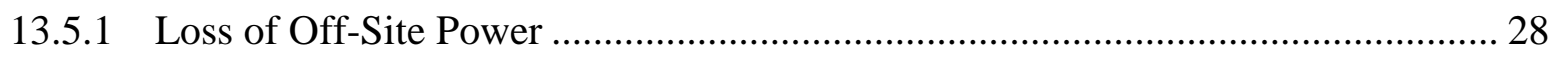

13.5.2 Loss of Both Shutdown Pumps........................................................................... 29

13.5.3 Seizure of One Primary Coolant Pump................................................................ 29

13.5.4 Throttling of Primary Coolant Flow to the Outer Plenum ........................................ 29

13.5.5 Throttling of Primary Coolant Flow to the Inner Plenum...................................... 30

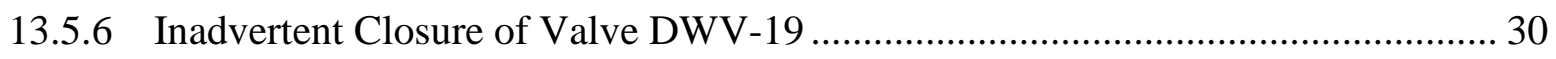

13.6 Mishandling or Malfunction of Fuel ..................................................................... 30

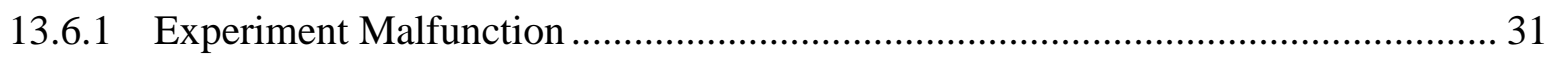

13.6.2 Loss of Normal Power ...................................................................................... 31

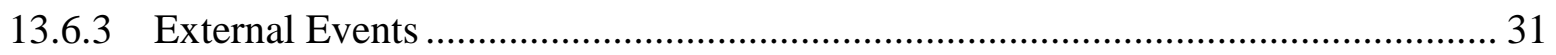

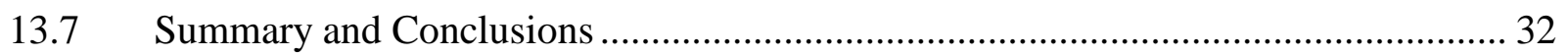

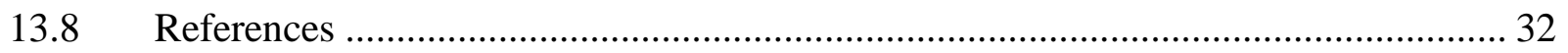

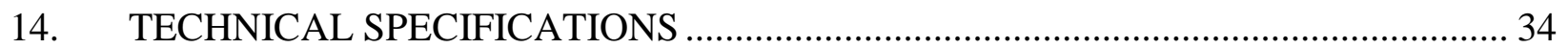

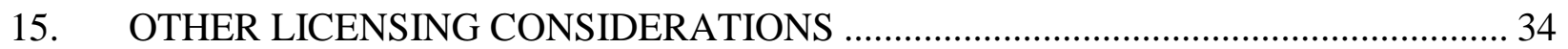




\section{LIST OF TABLES}

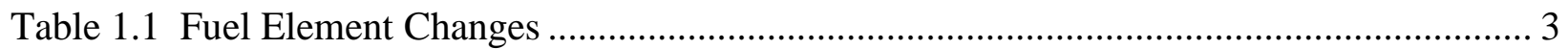

Table 4-1 Fuel Element Properties and Tolerance Assumptions, Pt. 1 ..................................... 8

Table 4-2 Fuel Element Properties and Tolerance Assumptions, Pt. 2 ..................................... 9

Table 4-3 Summary of Core Nuclear Parameters for HEU and LEU Fuels .............................. 12

Table 4-4 Hot Channel Factors and References to Underlying Tolerances (Cuadra, 2011) ........ 20

\section{LIST OF FIGURES}

Figure 4-1 NBSR Vessel Internals and Reactor Core .................................................... 6

Figure 4-2 NBSR Fuel Element ................................................................................... 7

Figure 4-3 Cross Sectional View of Fuel Element (Dimensions in Inches) ................................ 7 


\section{ACKNOWLEDGMENTS}

The authors benefitted greatly from the close support of the staff at the NIST Center for Neutron Research, which operates the NBSR. We thank Sean O’Kelly, Michael Rowe, and Robert Williams for their close collaboration. The authors appreciate the financial support of the National Nuclear Security Administration and the project management of John Stevens at Argonne National Laboratory. Thanks also to Lynda Fitz who ably performed all the administrative work for this report. 


\section{GENERAL DESCRIPTION OF THE FACILITY}

In this chapter there will be an overview of the conversion from HEU to LEU fuel. The following summarizes information known to date.

\subsection{Summary Description of Changes}

The NBSR is a heavy water $\left(\mathrm{D}_{2} \mathrm{O}\right)$ cooled, moderated, and reflected, tank-type reactor that operates at a design power of 20 MWth. The NBSR is cooled by forced circulation upward through two concentric plenums within the reactor core. There is no pulsing capability in the NBSR. There are thirty fuel elements in the core on a triangular pitch. The fuel elements are split axially into two halves with a gap located between the two halves at the vertical mid-plane of the core. This gap allows the beam tubes to be pointed directly at the mid-plane of the core so that thermal neutrons can escape for use in thermal and cold neutron scattering research while minimizing contamination from fast neutrons and gamma rays. Each half-element encapsulates seventeen curved fuel plates in the materials test reactor (MTR) geometry. The control elements within the NBSR consist of four semaphore-type shim safety arms and a single automatic regulating rod. Figure 1-1 shows a schematic of the reactor core.

The NBSR is operated for 38.5 day cycles. At the end of each cycle four fuel elements are removed from the core. The remaining 26 fuel elements are moved to new positions and four fresh, unirradiated fuel elements are inserted into the core. Fourteen of the thirty fuel elements are in the core for seven cycles and sixteen fuel elements remain for eight cycles.

The large volume and spacing within the core provides very flexible capabilities for thermal neutron irradiation. Insertion of eight radial beam tubes and two cold neutron sources into the plane of the fuel gap allows high intensity, low energy beams of neutrons to be extracted. A pneumatic rabbit system provides researchers with the ability to automatically inject samples into the core region of the reactor while thimbles provide for manual sample loading.

In normal operation the NBSR is cooled by forced convection of the $\mathrm{D}_{2} \mathrm{O}$ coolant. A large $\mathrm{D}_{2} \mathrm{O}$ hold-up tank and a $\mathrm{D}_{2} \mathrm{O}$ hold-up pan ensure adequate coolant supply in the event of a piping rupture. The inner reserve tank is located in the top reflector and is drained through two nonisolable pipes at the bottom of the tank. These pipes feed a flow distributor that routes emergency cooling to the individual fuel elements. A secondary hold up pan keeps the bottom half of the individual fuel elements immersed in coolant and collects water from the inner reserve tank that splashes out of the distributor pan or runs down the outside of the fuel elements.

There are several $\mathrm{D}_{2} \mathrm{O}$ reflectors in the NBSR. During refueling the top reflector is drained to slightly above the top of the active core. This level is maintained by the low-level overflow pipe that is concentric with the overflow pipe. During abnormal operation, a third overflow pipe, concentric with the fuel transfer chute, serves as a moderator dump to drop the $\mathrm{D}_{2} \mathrm{O}$ level to just above the active core for emergency shutdown.

A complete description of the NBSR reactor and support facility is provided in the current Safety Analysis Report (SAR) (NIST, 2010a). The only change that will be made in the NBSR reactor 
because of the conversion is the change in the fuel meat composition within the fuel plates and the thickness of the fuel meat and the aluminum cladding. The external dimensions of the fuel plates remain the same. A description of the change in the fuel elements is given below.

\subsubsection{Fuel Element Changes}

Presently the NBSR is fueled with high-enriched uranium (HEU) with a nominal ${ }^{235} \mathrm{U}$ enrichment of $93 \%$. The fuel is $\mathrm{U}_{3} \mathrm{O}_{8}$ in an aluminum powder dispersion that is clad in aluminum alloy. Each fuel element is constructed of 17 plates in each upper and lower half (34 plates per fuel element) and is constructed in the MTR curved plate geometry. Each plate is 13 in $(33.02 \mathrm{~cm})$ long with 11 in $(27.94 \mathrm{~cm})$ of active fuel length. The thickness of fuel in each plate is 0.020 in $(0.0508 \mathrm{~cm})$, equivalent to a volume of $9.05 \mathrm{in}^{3}\left(148 \mathrm{~cm}^{3}\right)$ of fuel per halfelement. Each HEU fuel element has a mass of $350 \pm 3.4 \mathrm{~g}$ of ${ }^{235} \mathrm{U}$. The aluminum cladding is 0.015 in $(0.0381 \mathrm{~cm})$ thick on each side.

The fuel meat for the low-enriched uranium (LEU) conversion of the NBSR is U10Mo metal foils with aluminum alloy cladding. The fuel element geometry for the LEU fuel is identical to the geometry presently used for the HEU fuel with the exception of the thickness of the fuel meat and the clad. Data for the U10Mo fuel are given in Table 1.1 along with data for the existing HEU fuel (Hanson, 2011a). The thickness of the LEU fuel foils is 0.0085 in $(0.0216 \mathrm{~cm})$ with a total volume of $3.8 \mathrm{in}^{3}\left(62.3 \mathrm{~cm}^{3}\right)$ per half-element. The engineering specification on fuel foil thickness is $0.0085 \mathrm{in}$. The rolling tolerance of the fuel foils is $\pm 0.001 \mathrm{in}$, so the fuel thickness is specified as $0.0085 \pm 0.001 \mathrm{in}$. The ${ }^{235} \mathrm{U}$ content of each LEU fuel element is $383 \pm 4 \mathrm{~g}$, where the uncertainty is only due to the uncertainty in the molybdenum content of the LEU fuel. The $10 \%$ weight specification for molybdenum has an uncertainty of $\pm 1 \%$. There is an uncertainty in ${ }^{235} \mathrm{U}$ content due to enrichment uncertainty and an uncertainty in total weight of the foil that are currently unknown. The thickness of the aluminum cladding for the LEU fuel is 0.0208 in $(0.053 \mathrm{~cm})$ on each side. 
Table 1.1 Fuel Element Changes

\begin{tabular}{|l|c|c|}
\hline & HEU & LEU \\
\hline${ }^{235} \mathrm{U}$ grams & 350 & 383 \\
\hline${ }^{238} \mathrm{U}$ grams & 26 & 1556 \\
\hline O grams & 68 & 0 \\
\hline Al grams & 625 & 0 \\
\hline Mo grams & 0 & 215 \\
\hline Total grams & 1069 & 2154 \\
\hline & 3.61 & \\
\hline Fuel density $\left(\mathrm{g} / \mathrm{cm}^{3}\right)$ & $0.02(0.0508)$ & $0.0085(0.0216)$ \\
\hline Fuel thickness in $(\mathrm{cm})$ & $2.415(6.134)$ & $2.415(6.134)$ \\
\hline Fuel width, in $(\mathrm{cm})$ & $11(27.94)$ & $11(27.94)$ \\
\hline Fuel length, in $(\mathrm{cm})$ & 148 & 62.3 \\
\hline Fuel volume $\left(\mathrm{cm}^{3}\right)$ & & \\
\hline & $13(33.2)$ & $13(33.2)$ \\
\hline Fuel plate length, in (cm) & $2.68(6.8)$ & $2.68(6.8)$ \\
\hline Fuel plate width, in (cm) & $0.050(0.127)$ & $0.050(0.127)$ \\
\hline Fuel plate thickness, in $(\mathrm{cm})$ & $5.5(13.97)$ & $5.5(13.97)$ \\
\hline Fuel plate radius of curvature, in $(\mathrm{cm})$ & & \\
\hline & 70 & 56 \\
\hline Average U-235 burnup, \% & \multicolumn{2}{|l}{} \\
\hline
\end{tabular}




\section{SITE CHARACTERISTCS}

There are no changes to the site characteristics as a result of conversion. This chapter will not be needed in the conversion SAR. Any updates to the chapter will be to address unrelated site changes that have not been documented in the current SAR and/or editorial changes.

\section{DESIGN OF STRUCTURES, SYSTEMS, AND COMPONENTS}

It is not expected that there will be any changes to principal architectural and engineering design bases for the structures, systems and components of the NBSR as a result of conversion. This chapter will not have any changes other than editorial changes in the conversion SAR. 


\section{REACTOR DESCRIPTION}

This chapter contains the bulk of the information on the changes due to conversion. A draft of this chapter as it would be submitted to NRC is available (Diamond, 2012). The following is a summary of what is found in that document and additional information.

\subsection{Summary Description}

The NBSR is a heavy water $\left(\mathrm{D}_{2} \mathrm{O}\right)$ cooled, moderated, and reflected, tank-type reactor that operates at a design power of 20 MWth. A general description is given in Section 1.1 above. A complete description of the NBSR reactor and support facility is provided in the current Safety Analysis Report (SAR) (NIST, 2010a). The only change that will be made in the NBSR reactor because of the conversion is the change in the fuel meat composition within the fuel plates and the thickness of the fuel meat and the aluminum cladding. The external dimensions of the fuel plates remain the same. Figure 4-1 shows the vessel internals and reactor core.

\subsection{Reactor Core}

\subsubsection{Reactor Fuel}

\subsubsection{Fuel Element Description}

Presently, the NBSR is fueled with high-enriched uranium (HEU) with a nominal ${ }^{235} \mathrm{U}$ enrichment of $93 \%$. The fuel meat is $\mathrm{U}_{3} \mathrm{O}_{8}$ in an aluminum powder dispersion that is clad in aluminum alloy. Each fuel element is constructed of 17 plates in each upper and lower half (34 plates per fuel element) and is constructed in the MTR curved plate geometry. The proposed fuel meat for the low-enriched uranium (LEU) conversion of the NBSR is U10Mo metal foils with aluminum cladding. The fuel element geometry for the LEU fuel is identical to the geometry presently used for the HEU fuel with the exception of the thickness of the fuel meat and the clad. A discussion of the fuel element is given in Section 1.1.1 above. Nominal fuel characteristics are given in Table 1.1. A cut-away drawing of the fuel element is in Figure 4-2 and a cross sectional view with dimensions is given in Figure 4-3. Table 4-1 and Table 4-2 provide nominal values and tolerance assumptions for fuel element properties including geometry, material, fission density limit, and thermal properties. 


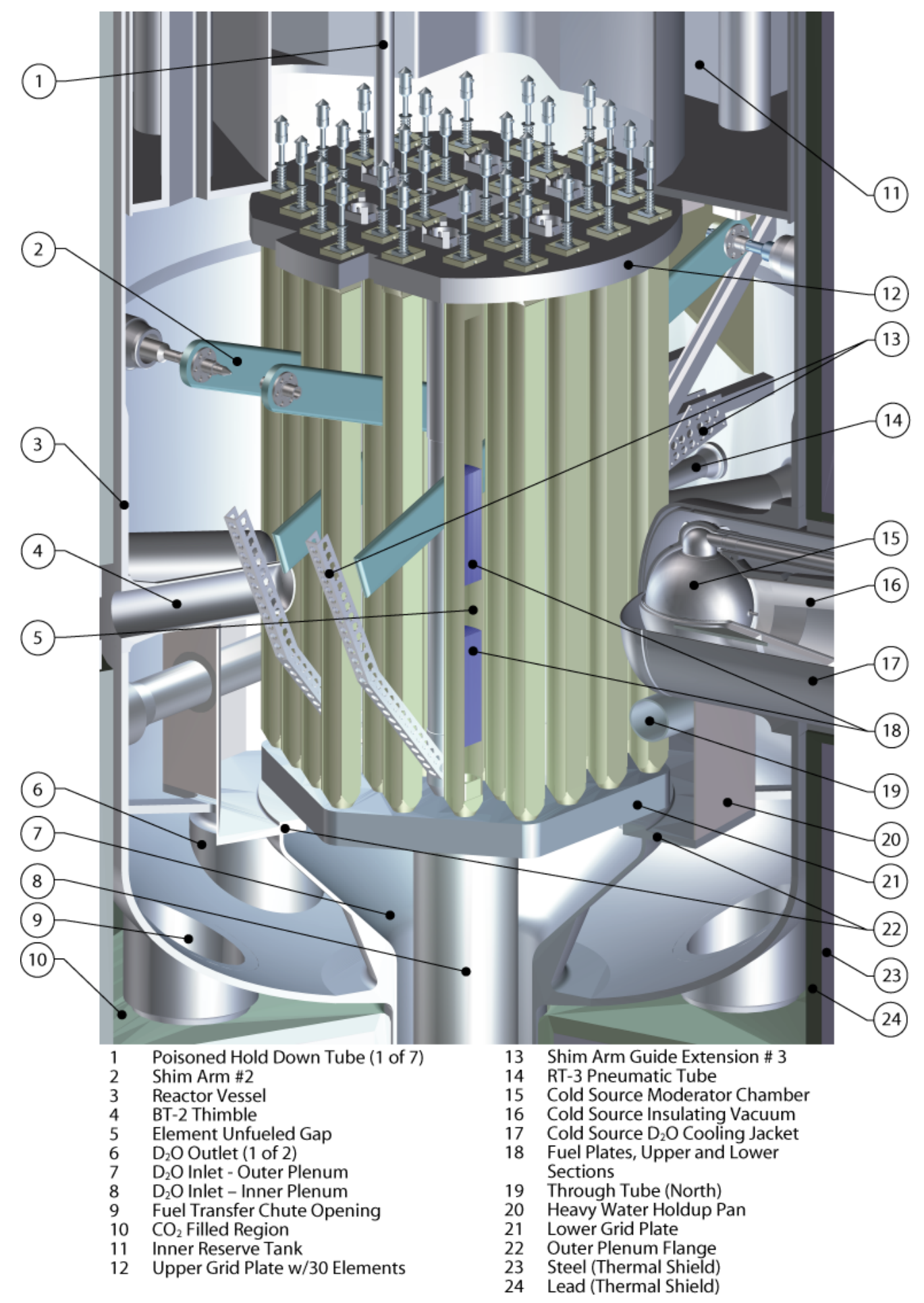

Figure 4-1 NBSR Vessel Internals and Reactor Core 


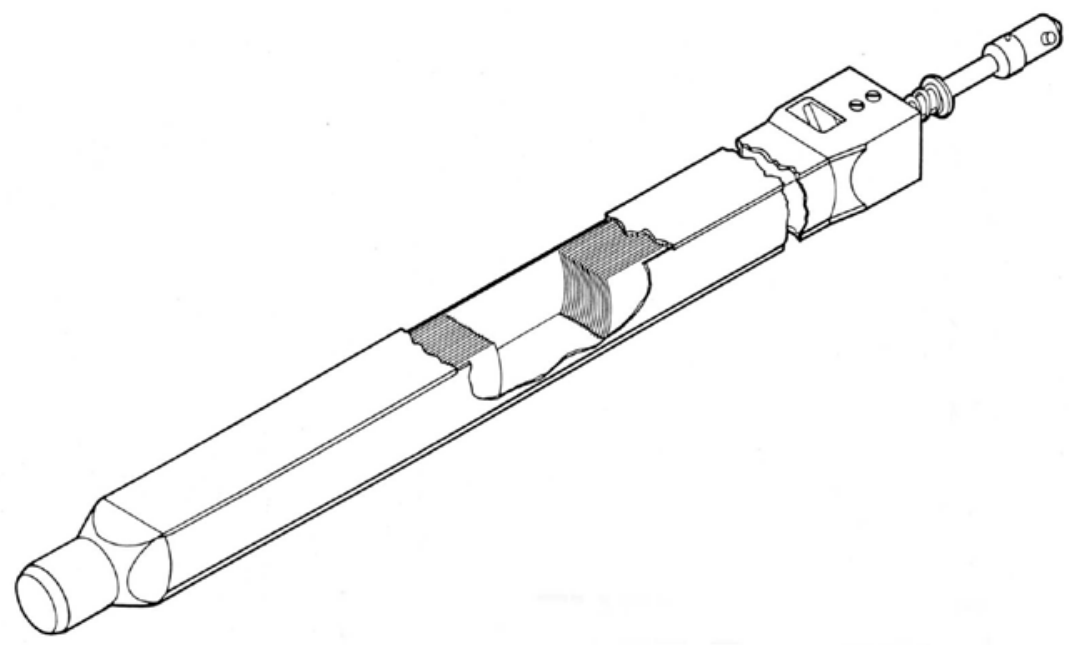

Figure 4-2 NBSR Fuel Element

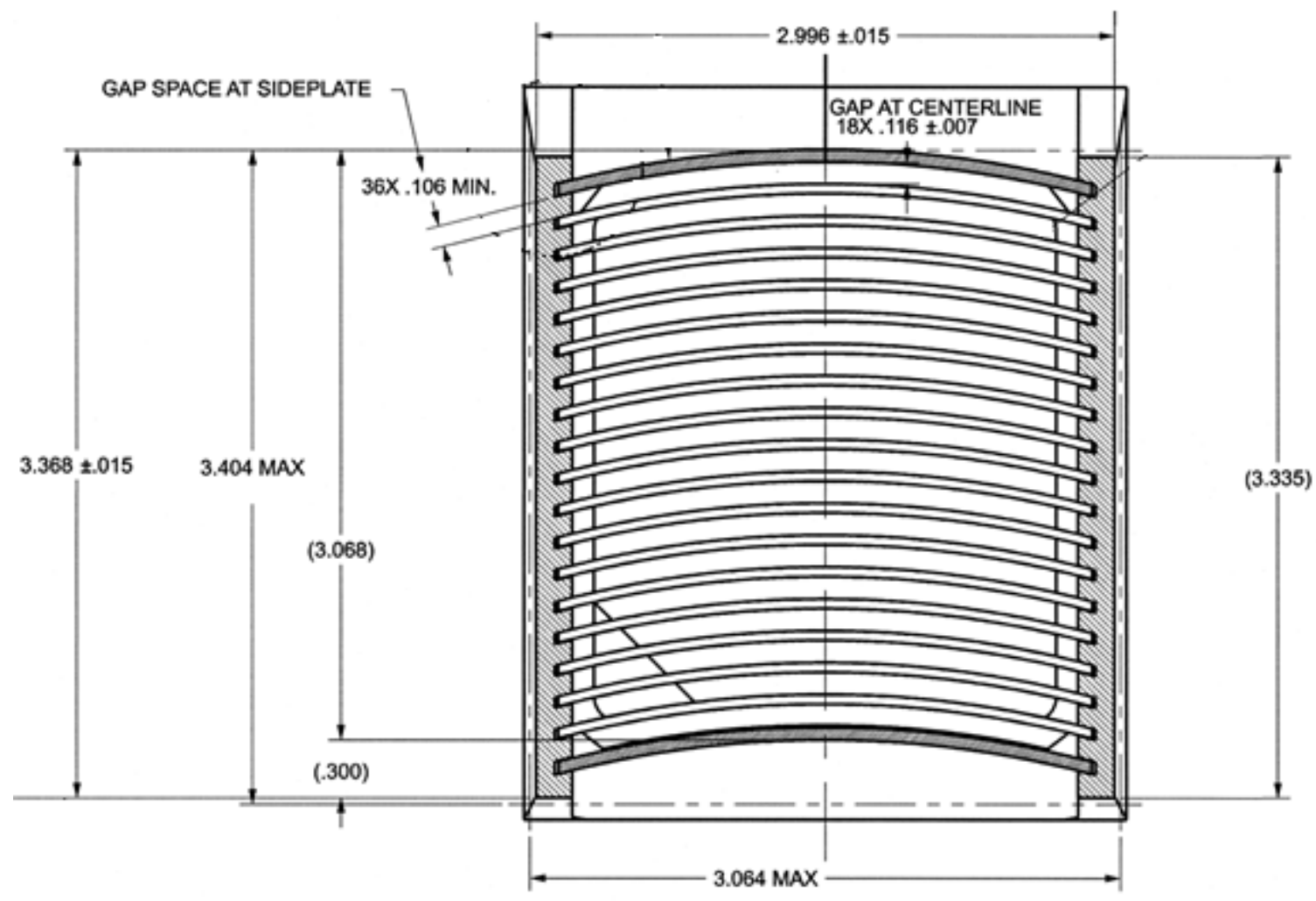

Figure 4-3 Cross Sectional View of Fuel Element (Dimensions in Inches) 
Table 4-1 Fuel Element Properties and Tolerance Assumptions, Pt. 1

\begin{tabular}{|c|c|c|c|}
\hline Parameter & HEU Specification & LEU Analysis Assumes* & Reference \\
\hline Average Channel Dimensions & $116 \mathrm{mil} \pm 7 \mathrm{mil}$ & $116.0 \mathrm{mil} \pm 11 \mathrm{mil}$ & (Cuadra, 2011) \\
\hline Local Channel Dimensions & $116 \mathrm{mil} \pm 10 \mathrm{mil}$ & $116 \mathrm{mil} \pm 15 \mathrm{mil}$ & (Cuadra, 2011) \\
\hline Plate Thickness & $50 \mathrm{mil}$ & $50 \mathrm{mil}$ & (NIST, 2010a) \\
\hline Clad Thickness & $15 \mathrm{mil}$ & $\begin{array}{l}20.8 \text { mil (including } 1 \\
\text { mil Zr layer) }\end{array}$ & (NIST, 2010a) \\
\hline $\begin{array}{l}\text { Minimum Clad Thickness } \\
\text { (not including scratch) }\end{array}$ & 10.5 mil, not used in safety analysis & $\begin{array}{l}\text { TBD, not used in safety } \\
\text { analysis. }\end{array}$ & (NIST, 2010a) \\
\hline Clad Scratch Maximum Depth & $\begin{array}{c}<5 \text { mil (over fuel meat), not used in } \\
\text { safety analysis }\end{array}$ & $\begin{array}{l}\text { TBD, not used in safety } \\
\text { analysis. }\end{array}$ & (NIST, 2010a) \\
\hline Clad Dent Maximum Depth & 6 mil, not used in safety analysis & $\begin{array}{l}\text { TBD, not used in safety } \\
\text { analysis. }\end{array}$ & (NIST, 2010a) \\
\hline Fuel Meat & $\mathrm{U}_{3} \mathrm{O}_{8}$ Dispersion in $\mathrm{Al}$ & $\begin{array}{c}\text { U-Mo } \\
\text { Mo content: } 10 \% \pm 1 \%\end{array}$ & \\
\hline Fuel Meat Thickness & 20 mil & $8.5 \mathrm{mil} \pm 1 \mathrm{mil}$ & \\
\hline Bonding Integrity & $\begin{array}{l}\text { Fuel is subjected to blister test at } 482^{\circ} \mathrm{C} \\
\pm 11^{\circ} \mathrm{C} \text { for at least one hour. After } \\
\text { cooling, the plates are visually } \\
\text { inspected for evidence of blisters. }\end{array}$ & $\begin{array}{l}\text { Debond characterization } \\
\text { and tolerances TBD }\end{array}$ & (NIST, 2010b) \\
\hline
\end{tabular}

* The LEU tolerances in this table are conservative assumptions for the purposes of informing the statistical analysis detailed in Section 4.6. The LEU tolerances in this table are considered to be unacceptably large, and the final LEU tolerances should be significantly lower than those presented here. 
Table 4-2 Fuel Element Properties and Tolerance Assumptions, Pt. 2

\begin{tabular}{|c|c|c|c|}
\hline Parameter & HEU Specification & LEU Analysis Assumes* & Reference \\
\hline $\begin{array}{l}\text { Local Fuel Homogeneity (0.080 in. x } 1.0 \\
\text { in.) }\end{array}$ & $112 \%$ of nominal & $118 \%$ of nominal & (Cuadra, 2011) \\
\hline Average U-235 Fuel Loading (plate) & $10.294 \mathrm{~g} \pm 0.2 \mathrm{~g}$ & $11.265 \mathrm{~g} \pm 0.3 \mathrm{~g}$ & (Cuadra, 2011) \\
\hline Fission Density Limit & $2.6 \mathrm{E} 21$ fission/cc & 7.9E21 fission/cc & \\
\hline U-10Mo Specific Heat & N/A & $\begin{array}{l}\text { Values used for U-Mo fuel } \\
\text { are provided in references. } \\
\text { Uncertainties are not } \\
\text { available or used in the } \\
\text { safety analysis. }\end{array}$ & $\begin{array}{l}\text { (Rest, 2006) } \\
\text { (Burkes, 2010) }\end{array}$ \\
\hline U-10Mo Thermal Conductivity & N/A & $\begin{array}{l}\text { Values used for U-Mo fuel } \\
\text { are provided in references. } \\
\text { Uncertainties are not } \\
\text { available or used in the } \\
\text { safety analysis. }\end{array}$ & $\begin{array}{l}\text { (Rest, 2006) } \\
\text { (Burkes, 2010) }\end{array}$ \\
\hline Oxide thickness & N/A & $\begin{array}{l}\text { TBD, irradiation test needed } \\
\text { to assess oxide formation on } \\
\text { LEU elements. }\end{array}$ & \\
\hline
\end{tabular}

* The LEU tolerances in this table are conservative assumptions for the purposes of informing the statistical analysis detailed in Section 4.6. The LEU tolerances in this table are considered to be unacceptably large, and the final LEU tolerances should be significantly lower than those presented here. 


\subsubsection{Technical Specifications}

There is one technical specification (NIST, 2009) concerning the fuel element design (as opposed to being related to operation). It is given below with the modifications (underlined or with strikeout) necessary to accommodate the LEU fuel:

Technical Specification 5.3, Reactor Core and Fuel:

1. The $20 \mathrm{MW}$ reactor core may consist of $303.0 \times 3.3$ inch $(7.6 \times 8.4 \mathrm{~cm})$ MTR curved plate-type fuel elements. The NBSR MTR-type fuel elements shall be such that the central 7 inches of the fuel element contains no fuel. The middle 6 inches of the aluminum in the unfueled region of each plate shall have been removed.

2. The side plates, unfueled outer plates, and end adaptor castings of the fuel element shall be aluminum alloy .

3. The fuel plates shall be $U_{3} \Theta_{8}$-dispersed in a matrix of aluminum uranium-molybdenum alloy foils clad with aluminum alloy.

Basis:

1. The neutronic and thermal hydraulic analysis was based on the use of 30 NBSR MTRtype thirty-four (34) plate fuel elements. The NBSR fuel element has a 7 inch centrally located unfueled area, in the open lattice array. The middle 6 inches of aluminum in the unfueled region has been removed. The analysis requires that the fuel be loaded in a specific pattern. Significant changes in core loading patterns would require a recalculation of the power distribution to ensure that the CHFR would be within acceptable limits.

2. and 3. The aluminum alloy clad dispersion fuels used in the MTR fuel elements have a 50 year record of reliability at many research reactors. uranium-molybdenum alloy foils have been qualified for use in the NBSR.

\subsubsection{Fabrication}

LEU fuel fabrication studies are presently underway as part of the GTRI fuel fabrication pillar. Information on LEU fuel fabrication is not yet available.

\subsubsection{Control Elements}

The reactivity control mechanism for the LEU-fueled NBSR will not be changed from the HEUfueled NBSR. The specifications and operating principles of the shim safety arms, regulating rod, and moderator dump will not be changed. The reactivity worth of the shim safety arms, regulating rod, and emergency moderator dump are discussed in Section 4.5.2. 


\subsubsection{Neutron Moderator and Reflector}

The $\mathrm{D}_{2} \mathrm{O}$ moderator and reflector for the LEU-fueled NBSR will not be changed from the HEUfueled NBSR. The specifications and operating principles of the moderator and reflector will not be changed.

\subsubsection{Neutron Startup Source}

The startup source is rarely utilized in the NSBR. In the event that the startup source is used, no changes will be made to the startup source or the startup source insertion procedure.

\subsubsection{Core Support Structure}

The core support structure for the LEU-fueled NBSR will not be changed from the HEU-fueled NBSR. The specifications and operating principles of the core support structure will not be changed. The fuel elements are held in place within an upper and lower grid plate. They are locked down against the upper grid plate with a spring loaded pin. When the forced flow is initiated, the force is enough that the fuel elements will lift from the lower grid plate and allows $\sim 4 \%$ of the coolant to bypass the fuel element. This had been verified for HEU fuel and will be verified via testing at Oregon State University for LEU fuel.

\subsection{Reactor Vessel}

The reactor vessel for the LEU-fueled NBSR will not be changed from that for the HEU-fueled NBSR. The specifications and operating principles of the reactor vessel will not be changed.

\subsection{Biological Shield}

The shielding surrounding the NBSR is an integral part of the confinement building, installed during the construction of the building. It was designed for 20-MW operation. Experience has demonstrated the adequacy of the design. Chapter 10 of (NBS, 1966) contains a description of the design considerations for the construction of the biological shield. The biological shield of the NBSR will not be altered for the conversion to LEU fuel. Except for the beam ports the biological shield is a minimum of 74 in $(188 \mathrm{~cm})$ of concrete surrounding an 8 in $(20 \mathrm{~cm})$ steel thermal shield. The thermal shield has an inner lining of 2 in $(5 \mathrm{~cm})$ of lead. Calculations indicate that in general less radiation will leak through the biological shield with the LEU fuel than with the HEU fuel (Diamond, 2012).

\subsection{Nuclear Design}

This section will provide a summary description of the methodology used for the nuclear design as well as results for significant parameters. Inventories used for both the HEU and LEU fuels were generated with MCNPX, v. 2.6.0 (Pelowitz, 2011) using the BURN option. Analyses of the parameters were with either MCNPX, v. 2.6.0 or MCNP5 (Kiedrowski, 2005). Results are provided for both the HEU and LEU cores to evaluate the effect of conversion. The SU 
condition is the most reactive point in the cycle and hence, bounding for certain analyses. For some parameters results are given for both SU and EOC conditions. The latter state point is bounding in transients in which the reactor shutdown is important since differential shim arm worth is lowest when they are initially withdrawn at EOC. A summary of the significant parameters is given in Table 4-3 for both the HEU and LEU cores. More detailed information is found in (Diamond, 2012).

Table 4-3 Summary of Core Nuclear Parameters for HEU and LEU Fuels

\begin{tabular}{|l|c|c|}
\hline \multicolumn{1}{|c|}{ Parameter } & HEU & LEU \\
\hline Excess reactivity $(\% \Delta \mathrm{k} / \mathrm{k})$ & 6.7 & 6.3 \\
\hline Shutdown margin with highest worth shim arm $(\mathrm{No} .3)$ out $(\% \Delta \mathrm{k} / \mathrm{k})$ & -10.1 & -10.8 \\
\hline $\mathrm{k}_{\text {eff }}$ with moderator at dump level, SU & 0.9857 & 0.9849 \\
\hline $\mathrm{k}_{\text {eff }}$ with moderator at dump level, EOC & 0.9124 & 0.9215 \\
\hline Shim arm worth, SU $(\% \Delta \mathrm{k} / \mathrm{k})$ & 24.9 & 24.2 \\
\hline Shim arm worth, EOC (\% $\Delta \mathrm{k} / \mathrm{k})$ & 27.2 & 26.0 \\
\hline Regulating rod worth, SU $(\% \Delta \mathrm{k} / \mathrm{k})$ & 0.50 & 0.53 \\
\hline Regulating rod worth, EOC $(\% \Delta \mathrm{k} / \mathrm{k})$ & 0.45 & 0.43 \\
\hline Moderator temperature coefficient, SU $\left(\% \Delta \mathrm{k} / \mathrm{k} /{ }^{\circ} \mathrm{C}\right)$ & -0.0313 & -0.0280 \\
\hline Moderator temperature coefficient, EOC $\left(\% \Delta \mathrm{k} / \mathrm{k} /{ }^{\circ} \mathrm{C}\right)$ & -0.0275 & -0.0228 \\
\hline Void coefficient, all thimbles voided, SU $(\% \Delta \mathrm{k} / \mathrm{k} / \mathrm{liter})$ & -0.047 & -0.040 \\
\hline Void coefficient, all thimbles voided, EOC $(\% \Delta \mathrm{k} / \mathrm{k} / \mathrm{liter})$ & -0.039 & -0.049 \\
\hline Void coefficient, all FEs voided, SU $(\% \Delta \mathrm{k} / \mathrm{k} / \mathrm{liter})$ & -0.016 & -0.018 \\
\hline Void coefficient, all FEs voided, EOC $(\% \Delta \mathrm{k} / \mathrm{k} / \mathrm{liter})$ & -0.019 & -0.015 \\
\hline Reactivity insertion for CNS flooded, SU $(\% \Delta \mathrm{k} / \mathrm{k})$ & 0.24 & 0.19 \\
\hline Reactivity insertion for CNS flooded, EOC $(\% \Delta \mathrm{k} / \mathrm{k})$ & 0.25 & 0.20 \\
\hline Reactivity insertion for flooding one tangential BT, SU $(\% \Delta \mathrm{k} / \mathrm{k})$ & 0.27 & 0.28 \\
\hline Reactivity insertion for flooding one tangential BT, EOC $(\% \Delta \mathrm{k} / \mathrm{k})$ & 0.20 & 0.19 \\
\hline Peak half-element relative power, SU & 1.28 & 1.35 \\
\hline Peak half-element relative power, EOC & 1.18 & 1.15 \\
\hline Peak half-element relative power with misloaded FE & 1.93 & 1.83 \\
\hline Delayed neutron fraction, SU & 0.00665 & 0.00650 \\
\hline Delayed neutron fraction, EOC & 0.00661 & 0.00648 \\
\hline Recommended prompt neutron lifetime, SU $(\mu \mathrm{s})$ & 650 & 600 \\
\hline Recommended prompt neutron lifetime, EOC $(\mu \mathrm{s})$ & 750 & 700 \\
\hline Steady state CHFR, SU & 4.03 & 4.12 \\
\hline Steady state CHFR, EOC & 3.99 & 3.96 \\
\hline Steady state OFIR, SU & 5.50 & 5.61 \\
\hline Steady state OFIR, EOC & 6.17 & 6.15 \\
\hline Peak heat flux, SU $\left(\mathrm{kW} / \mathrm{m}^{2}\right)$ & 1472 & 1443 \\
\hline
\end{tabular}




\subsubsection{Neutronic and Burn-up Model of the NBSR}

This section will summarize the neutronics model using Monte Carlo neutron transport and the associated fuel burn-up modeling. Information on the methodology is currently found in (Hanson, 2005a) and (Hanson, 2011b).

\subsubsection{Reactivity Calculations}

\subsubsection{Excess Reactivity and Shutdown Margin}

NBSR Technical Specification 3.1.2, Reactivity Limitations, states that the core cannot be loaded such that the excess reactivity will exceed $15 \% \Delta \mathrm{k} / \mathrm{k}$ and it also states that the NBSR shall not be operated if it cannot be kept shutdown with the most reactive shim arm fully retracted. To determine if these conditions are met, $\mathrm{k}_{\text {eff }}$ was calculated under the following conditions: all shims inserted (shutdown reactivity), all shim arms withdrawn (excess reactivity), and three of the four shim arms inserted with the other withdrawn (shutdown margin, SDM). The calculation was performed at the most reactive state point in the cycle, which is SU with four fresh fuel elements and no ${ }^{135}$ Xe poison. Results are given in (Hanson, 2011a) and demonstrate that neither the HEU nor the LEU equilibrium cores exceed the excess reactivity limit of $15 \% \Delta \mathrm{k} / \mathrm{k}$ and that with both the HEU and LEU fuels the core can be maintained in a shutdown condition with the most reactive shim arm withdrawn. Note that these calculations are for fresh (or with no significant burn-up) cadmium shim arms. Future calculations will address this aspect of the analysis.

\subsubsection{Moderator Dump}

The NBSR has a pipe, referred to as the moderator dump, whose entrance is just above the fueled portion of the core. If an emergency situation requires it, the pipe can be used to drain the coolant to that dump level leaving the core with no upper reflector. The lack of an upper reflector results in the reactor becoming subcritical.

Calculations of $k_{\text {eff }}$ when the coolant is lowered to the dump level were performed with the shim arms and regulating rod fully withdrawn. The calculations are done for the two state points of most concern, SU and EOC. These results are given in (Hanson, 2011a) and demonstrate that the NBSR can be kept subcritical with either HEU or LEU fuel under all conditions if the coolant were to be lowered to the dump level.

\subsubsection{Reactivity Worth of the Shim Safety Arms and Regulating Rod}

The reactivity of the NBSR is controlled with four cadmium shim arms that are rotated through the core in a semaphore fashion. The worth of fresh (assuming no burn-up of the cadmium in the shim arms) shim arms was calculated using the fuel inventories at SU and EOC and calculating $k_{\text {eff }}$ as a function of shim arm position (moving all four of the shim arms together). The shim arm worth curves for the HEU and LEU cores are available in (Hanson, 2011a) and show that with LEU fuel, the total worth is slightly less than with the HEU fuel. More recent calculations with shim arms that have been in the core for 25 fuel cycles (shim arms are usually removed 
after 24 cycles) also show that there is adequate shutdown margin for both types of fuel when the shim arm poison is depleted.

The regulating rod is an aluminum rod located in the central core. It performs the automatic fine control of the reactivity between larger reactivity insertions when the shim arms are moved. As the uranium in the core fissions, excess reactivity is lost and that loss is compensated by a slow and continuous withdrawal of the regulating rod. When the regulating rod is nearly fully withdrawn the shims arms are moved outward and the regulating rod is re-inserted. The regulating rod works by adding a large volume of a weak absorber and displacing $\mathrm{D}_{2} \mathrm{O}$ when it is fully inserted. The total worth is analyzed in (Hanson, 2011a) and shows that the rod worth is slightly higher for the LEU fuel than for the HEU fuel.

\subsubsection{Moderator Temperature Reactivity Coefficient}

The moderator temperature reactivity coefficient (MTC) has an impact if there is an increase in temperature in the $\mathrm{D}_{2} \mathrm{O}$ moderator, coolant, and reflector. The MTC has been calculated for the HEU and LEU cores at SU and EOC. The MTC is negative so if there is an inadvertent power rise, and hence a heating of the moderator, there will be a negative feedback causing a reduction in power. The details of the analysis can be found in (Hanson, 2011a) and show that MTC does not change significantly after converting to LEU fuel.

\subsubsection{Void Reactivity Coefficient}

The NBSR is an under-moderated reactor and is sensitive to the presence of $\mathrm{D}_{2} \mathrm{O}$ throughout the core and reflector. Any decrease in $\mathrm{D}_{2} \mathrm{O}$ density within the NBSR will result in a negative reactivity insertion. This holds true for both the HEU and LEU cores. The void feedback coefficients were calculated as a function of $\mathrm{D}_{2} \mathrm{O}$ voiding within various locations in the NBSR core. The voiding process was modeled as a change in the density of the coolant and moderator. In the discussion of the MTC in Section 4.5.2.4, lowering the density of the moderator was shown to result in negative feedback so any process that results in void generation will likewise have negative feedback.

Voiding within a fuel element or irradiation thimble was calculated for the following cases:

- $\quad$ void all 2.5-in irradiation thimbles

- $\quad$ void all 3.5-in irradiation thimbles

- $\quad$ void all irradiation thimbles

- $\quad$ void the 7-in gap in the fuel elements

- void all of the fuel elements within the upper and lower bounds of the fueled regions

The methodology for this analysis was similar to the methodology for calculating the MTC and is explained in (Hanson, 2011a). The results demonstrate that a void forming anywhere within the NBSR will provide negative reactivity feedback of magnitude similar for the HEU and LEU cores. 


\subsubsection{Beam Tube Flooding}

Beam tube flooding was hypothesized to occur if a $\mathrm{D}_{2} \mathrm{O}$ cooled experiment in a beam tube were to leak, or a crack were to occur in a beam tube, a thimble, or the cold neutron source. Such an event would allow $\mathrm{D}_{2} \mathrm{O}$ to enter areas that are normally filled with air or vacuum and introduce a positive reactivity. Results for the three situations of interest were analyzed in (Hanson, 2011a) and show that the reactivity added is less than the $0.5 \% \Delta \mathrm{k} / \mathrm{k}$ used to analyze the maximum reactivity insertion accident (Chapter 13). These calculations assumed a complete flooding of the beam tubes.

\subsubsection{Light Water Ingress}

The NBSR is a $\mathrm{D}_{2} \mathrm{O}$ cooled and moderated system. The $\mathrm{D}_{2} \mathrm{O}$ used in the NBSR is $99.97 \%$ pure with $0.03 \% \mathrm{H}_{2} \mathrm{O}$. Any additional light water contamination with either HEU or LEU fuel would have a negative effect on the reactivity of the NBSR as shown in the analysis discussed in (Hanson, 2011a).

\subsubsection{Power Distribution and Energy Spectra Calculations}

\subsubsection{Radial Power Distribution}

The radial power distributions, which show the average power generated in each half fuel element, will be shown in this section. (Diamond, 2012) provides results for the power distribution and it is shown that there are no significant changes in peaking factors when converting to LEU fuel. However, with HEU fuel, fuel element power is highest at the core periphery whereas with LEU fuel, the power is peaked in the center of the core. This reduces the flux of neutrons available at the beam tubes and cold sources by $5-10 \%$

\subsubsection{Axial and Plate-wise Power Distributions}

An MCNP model of the NBSR was developed in which each fuel plate was divided into $2 \mathrm{x} 2 \mathrm{~cm}$ (nominally) squares. The fission rate density, which is proportional to the local power density, was calculated for each square. The resulting axial and plate-by-plate profiles in terms of heat flux (proportional to fission rate density) can be found in (Brown, 2013a) and will be presented in this chapter of the SAR. Thermal-hydraulic analyses are performed using these threedimensional power distributions to ensure the reactor can be safely operated with the LEU fuel at all points in the fuel cycle. Information on how they are used in the thermal-hydraulic analysis can be found in (Baek, 2012). More detailed power distributions for the transverse and axial dimensions have also been generated in spite of the fact that only three transverse mesh intervals are needed for the thermal-hydraulic analysis (Cheng, 2010). The maximum fission rate density calculated for the core is $4.03 \times 10^{14}$ fissions $/ \mathrm{cm}^{3}$-s. Note that the power distribution analysis does not take into account the burnup distribution within a half-element and therefore, the results being used for the safety analysis are very conservative (Brown, 2013b). 


\subsubsection{Energy Spectra}

A comparison of the energy spectra throughout the core after conversion was carried out using the MCNPX model of the core (Brown, 2012). The results showed that qualitatively the spectrum looks similar for both the HEU and LEU cores but the former is larger quantitatively in the thermal region. This will be presented in this section of the SAR.

\subsubsection{Reactor Kinetics Parameters}

The reactor kinetics parameters that will be discussed in this section are the precursor fractions for 14 delayed neutron groups, their decay constants, and the prompt neutron lifetime. These parameters are used in the point reactor kinetics model used for the accident analyses. The details of the derivation of these parameters are given in (Hanson, 2012b). Subsections will be for the delayed neutron parameters from fission products, the delayed neutron parameters from photoneutrons, and for the prompt neutron lifetime calculation.

\subsubsection{Technical Specifications}

This section will contain the safety limits, limiting safety system settings (LSSSs), and limiting conditions for operation (LCOs) (NIST, 2009) that are changed as a result of conversion with respect to nuclear design parameters.

To maintain the integrity of the fuel cladding and prevent the release of significant amounts of fission products, Technical Specification (TS) 2.1, Safety Limit, defines the limit based on the blister temperature, which is $450^{\circ} \mathrm{C}\left(842^{\circ} \mathrm{F}\right)$ for the $\mathrm{HEU}$ fuel. At this writing, the blister temperature for LEU fuel is being investigated by the fuel development pillar at Idaho National Laboratory. No substantive changes relative to the HEU limit are expected.

No substantive changes are required for either the LSSSs or LCOs. However, since the fuel has changed, minor modifications must be made to several LCOs. These are shown using underlining and strikeout to show the changes.

LCO 3.1.2, Reactivity Limitations, must be modified to recognize that although the reactivity limits expressed in \% do not change, expressing them in dollars does change as the result of the change in delayed neutron fraction.

Specifications:

1. The maximum available excess reactivity for the reference core conditions shall not exceed $15 \% \Delta \rho$ (approximately $\$ z 022$ )

2. The reactor shall not be operated unless shutdown margin provided by the shim arm is greater than $0.68757 \% \Delta \rho(\$ 1.0)$ with:

a) The reactor in any core condition, and

b) All movable experiments in their most reactive condition.

LCO 3.1.4, Fuel Burnup, must be modified to account for the different fuel volume: 
Specification: the average fission density shall not exceed $\underline{5} 2 \times 10^{27} \underline{\text { fissions } / \mathrm{m}^{3}}$.

Basis: Fuel elements in the NBSR are burned for either seven or eight cycles. An eight cycle fuel element has an average fission density of approximately $4.441 .9 \times 10^{27}$ fissions $/ \mathrm{m}^{3}$. The $\mathrm{U}_{3} \Theta_{8}$ Al dispersion MTR fuets have been in widespread use for over 40 years. Extensive testing of ful plates has been performed to determine the limits on fission density as a function of fuel loading. Several measurements of swelling in fuel plates show that NBSR fuel, which is moderately loaded at 18\% is well below the curve that represents the allowable limit of bummup. Any other changes will be based on fuel qualification tests that will be performed.

\subsection{Thermal-Hydraulic Design}

\subsubsection{Design Basis}

The design basis of the thermal-hydraulic design of the NBSR is that there shall be no fuel damage during normal operation and no fuel damage resulting in release of fission products from any credible accident (see also Chapter 13). For normal operating conditions, the criterion chosen was that the heat transfer to the primary coolant shall not exceed critical heat flux (CHF) conditions, including any excursive instability; the latter being defined by "onset of flow instability" (OFI). This would preclude blistering and the potential for fuel damage. The temperature at which blistering might occur is the Safety Limit in the Technical Specifications and hence, also a criterion for fuel damage.

\subsubsection{Flow Distribution in the Core}

The flow geometry for the NBSR is discussed in detail in (Cheng, 2004) where critical dimensions, elevations and other pertinent data are given. The core consists of 30 fuel elements that are fed by two plenums at the bottom of the vessel. One plenum feeds the inner core consisting of six elements in the innermost area of the core), while the other feeds the remaining 24 elements. The primary coolant flow is distributed between these two plenums by the inherent flow resistance of the two different paths, and has been measured at total flows of up to $560 \mathrm{l} / \mathrm{s}$ (8700 gpm) as $148 \mathrm{l} / \mathrm{s}(2300 \mathrm{gpm})$ for the inner plenum and $412 \mathrm{l} / \mathrm{s}(6400 \mathrm{gpm})$ for the outer plenum. Approximately $4 \%$ of the flow bypasses the core (NBS, 1966). The inlet temperature for the coolant is $100^{\circ} \mathrm{F}\left(37.8^{\circ} \mathrm{C}\right)$ and the pressure drop across the core is $12 \mathrm{psi}\left(0.84 \mathrm{~kg} / \mathrm{cm}^{2}\right)$

\subsubsection{Power Distribution in the Core}

The power distribution in the core is assumed to be given by the fission density as calculated by the computer code MCNPX. This is a conservative assumption, as $14 \%$ of the energy is in the form of $\gamma$-rays and neutrons, and will be deposited much more uniformly throughout the core. A conservative estimate of the energy deposited in the fuel is 95\% (Hanson, 2005b). Another conservatism is the fact that burnup is assumed to be uniform over each half element. In reality the distribution of burnup in a half-element is roughly proportional to power density and this tends to lower high power densities. This does not apply to fresh fuel but, as will be discussed 
below, the highest powers are in burned fuel elements. The degree of conservatism that is the result of not taking into account the burnup distribution is discussed in (Brown, 2013b).

Many calculations have determined the fission rate in the fuel plates as a function of shim arm position and core depletion throughout the cycle. The model used represents the geometry of the system in great detail, and gives agreement with startup shim arm positions and liquid hydrogen cold source performance. The limiting case for the thermal-hydraulic design is the SU core. With four new fuel elements, criticality occurs when the shim safety arms are inserted furthest into the core. This insertion results in flux compression into the bottom half of the fuel elements.

For each fuel element in the core, the power produced in each plate is used to calculate a hot channel, which is the coolant channel into which the most heat is deposited from the fuel. The local fission rate, a conservative analog to the local energy deposition, was calculated assuming (nominal) 2x2 cm mesh throughout the core. The calculations were performed for both the HEU and LEU cores. Thermal-hydraulic analyses were performed using these three-dimensional power distributions to ensure the reactor can be safely operated at all points in the fuel cycle. The model allows definition of a "hot spot," the point with the highest energy deposition, and "hot stripe" the vertical fuel plate "stripe" with the highest energy deposition. A vertical hot stripe represents $1 / 3$ the width of a single fuel plate. In general, the "hot spots" are used for evaluation of the critical heat flux condition and the hot stripes are used for evaluation of the OFI condition. More details are given in (Baek, 2012).

\subsubsection{Determination of Limiting Conditions}

In order to determine how close the reactor operates to CHF or OFI a statistical methodology (Cheng, 2004 and Cuadra, 2011) is first used to determine acceptable limits. Cumulative distribution functions are obtained for critical heat flux ratio (CHFR), and onset of flow instability ratio (OFIR). The methodology is identical to that used for the licensing safety analysis in the past with two important changes: The correlation used for CHF has been changed from that due to Mirshak to one from Sudo-Kaminaga (Kaminaga, 1998) and the correlation for OFI is that of Saha-Zuber (Saha, 1974 and Oh, 1996) rather than Costa, which had been used in the past. These correlations are discussed in (Baek, 2013) along with their application.

\subsubsection{Critical Heat Flux}

The Sudo-Kaminaga correlation represents an improvement over the Mirshak correlation due to the enhanced geometric similarity, increased dependence on the full range of actual operating conditions in the NBSR, and an overall approach that is more mechanistic. It was developed for vertical rectangular channels in JRR-3 (Japan Research Reactor unit 3). The CHF experiments included the effect of mass flux, inlet subcooling, outlet subcooling, flow direction, pressure, as well as the channel configuration. Experiments were carried out within the range of pressure of 0.1 to $4 \mathrm{MPa}$, mass flux of $-25,800$ to $6250 \mathrm{~kg} / \mathrm{m}^{2}$-s, including stagnant flow conditions, inlet subcooling of 1 to $213 \mathrm{~K}$, outlet condition with subcooling of 0 to $74 \mathrm{~K}$ and quality of 0 to 1.0 , and the ratio of heated length to equivalent hydraulic diameter L/De of 8 to 240. The correlations proposed by Sudo and Kaminaga are mass flux and flow direction dependent and there are three separate regions, based on the dimensionless mass flux. 


\subsubsection{Onset of Flow Instability Correlation}

The most relevant instability for the NBSR, the Ledinegg static instability, has its origin in a simple effect. As water flow in a heated channel is reduced, a point will be reached where boiling will occur. At a later point significant amounts of vapor will be present in the channel. The presence of this vapor will increase the pressure drop, and when this effect is large enough, this increase will overwhelm the decrease in pressure drop arising from the flow decrease. This is known as the onset of flow instability. At this point, the overall pressure drop in the hot channel of a fuel element will increase, and flow will be reduced (if the channel spans an inlet and outlet header, with other, lower power channels in parallel). This condition causes a flow instability, which will result in rapid loss of adequate cooling for that channel.

The OFI is determined by assuming that the onset of net vapor generation is a conservative threshold for OFI, and the Saha-Zuber criteria are used.

\subsubsection{Statistical Analysis of Thermal-Hydraulic Parameters}

The statistical analysis uses a Monte Carlo method and assumes that each factor which contributes to the thermal-hydraulic variables of interest is normally distributed. The cumulative distribution functions (CDFs) are calculated for steady-state full power conditions, and are used to establish acceptance criteria for different hot channel factors (in particular CHFR and OFIR) under accident conditions. For each hot channel variable, the CDF was used to determine the limiting value such that there was a fixed probability of not exceeding this value. The probabilities considered were 90\%, 95\%, and 99.9\%. More information is given in (Cheng, 2004 and Cuadra, 2011).

Table 4-4 shows the dimensionless hot channel factors of interest for the HEU and LEU cores with their corresponding standard deviations $(\sigma)$, assuming a normal distribution. The source of information for these numbers is also given. The analyses assume a constant pressure, and constant thermal properties.

The fuel element plates in the LEU core have identical dimensions to the current HEU fuel, but have fuel meat composed of monolithic U10Mo rather than dispersion fuel. Additionally, the U10Mo foils are thinner than the dispersion fuel, so the portion of the fuel plates that cover the fuel (the cladding) will be thicker. Because of the change in the fabrication processes, the dimensional tolerances (local and average) and fuel loading tolerances (local and average) are different. The final tolerances are yet unknown, but scoping calculations, with uncertainties based on the HEU values, were performed to identify trends and provide guidance on "acceptable" values for the LEU tolerances. The tolerances have been chosen as 1.5 times the HEU values. Hence, for the LEU core all hot channel factors are the same with the following exceptions: The local and average channel dimensional tolerances considered are 0.075 and 0.0525 , respectively, and the local and average fuel loading tolerances considered are 0.1035 and 0.0173 , respectively.

The calculated values for CHFR and OFIR are used to assess the potential for fuel damage. The results for normal steady state operation, (Baek, 2013) are provided in this chapter and show 
very large margins to limiting conditions. Results for transient/accident conditions are given in Chapter 13.

Table 4-4 Hot Channel Factors and References to Underlying Tolerances (Cuadra, 2011)

\begin{tabular}{|c|c|c|c|c|}
\hline Source of Uncertainty & $\begin{array}{c}\text { HEU } \\
\text { Limit } \\
(*)\end{array}$ & HEU Reference & $\begin{array}{c}\text { LEU } \\
\text { Limit } \\
(*)\end{array}$ & LEU Reference \\
\hline $\begin{array}{l}\text { Reactor Power } \\
\text { Measurement }\end{array}$ & 0.025 & $\begin{array}{l}\text { Table 3.2-1 of (NBS, } \\
1980)\end{array}$ & 0.025 & HEU Value \\
\hline $\begin{array}{l}\text { Power Density } \\
\text { Calculation }\end{array}$ & 0.04 & $\begin{array}{l}\text { Table } 3.2-1 \text { of (NBS, } \\
1980)\end{array}$ & 0.04 & HEU Value \\
\hline $\begin{array}{l}\text { Channel Dimensional } \\
\text { Tolerance (local) }\end{array}$ & 0.05 & $\begin{array}{l}\text { NBSR Dwg \# E-04- } \\
\text { 016, Figure } 4.3 \text { (NBS, } \\
\text { 1966) }\end{array}$ & 0.075 & 1.5x(HEU Value) \\
\hline $\begin{array}{l}\text { Channel Dimensional } \\
\text { Tolerance (average) }\end{array}$ & 0.035 & $\begin{array}{l}\text { NBSR Dwg \# E-04- } \\
\text { 016, Figure } 4.3 \text { (NBS, } \\
\text { 1966) }\end{array}$ & 0.0525 & 1.5x(HEU Value) \\
\hline $\begin{array}{l}\text { Velocity Distribution } \\
\text { Measurement }\end{array}$ & 0.061 & $\begin{array}{l}\text { Sect. 4.7.4.5, 4.7.4.6 } \\
\text { (NBS, 1966) }\end{array}$ & 0.061 & HEU Value \\
\hline $\begin{array}{l}\text { Primary Flow Rate } \\
\text { Measurement }\end{array}$ & 0.022 & $\begin{array}{l}\text { Email message from } \\
\text { NIST/NCNR, 7/31/02 }\end{array}$ & 0.022 & HEU Value \\
\hline $\begin{array}{l}\text { Fuel Loading Tolerance } \\
\text { (local) }\end{array}$ & 0.069 & $\begin{array}{l}\text { Spec. for Aluminum } \\
\text { Clad Fuel Elements } \\
\text { (NIST, 2010B) }\end{array}$ & 0.104 & 1.5x(HEU Value) \\
\hline $\begin{array}{l}\text { Fuel Loading Tolerance } \\
\text { (average) }\end{array}$ & 0.0115 & $\begin{array}{l}\text { Spec. for Aluminum } \\
\text { Clad Fuel Elements } \\
\text { (NIST, 2010B) }\end{array}$ & 0.0173 & 1.5x(HEU Value) \\
\hline Pressure Measurement & 0 & Assumed constant & 0 & HEU Value \\
\hline $\begin{array}{l}\text { Heat Transfer } \\
\text { Correlation }\end{array}$ & 0.087 & Engineering judgment & 0.087 & HEU Value \\
\hline $\begin{array}{l}\text { Critical Heat Flux } \\
\text { Correlation }\end{array}$ & 0.202 & $\begin{array}{l}\text { Sudo-Kaminaga } \\
\text { correlation (Kaminaga, } \\
\text { 1998) }\end{array}$ & 0.202 & HEU Value \\
\hline $\begin{array}{l}\text { OFI Heat Flux } \\
\text { Correlation }\end{array}$ & 0.03 & $\begin{array}{l}\text { Saha-Zuber correlation } \\
\text { (Saha, 1974) }\end{array}$ & 0.03 & HEU Value \\
\hline
\end{tabular}

* Uncertainty limits represent $1 \sigma$ standard deviation assuming a normal distribution. When the referenced uncertainties are given as lower and upper limits, the range is assumed to represent a $\sqrt{12} \sigma$ value. 


\subsubsection{Shutdown Cooling}

The NBSR is equipped with shutdown cooling [see Chapter 5 in (NIST, 2010a)], which provides ample cooling for all shutdown conditions. One of the accidents analyzed (see Chapter 13) includes loss of off-site power (and hence main primary pumps), followed by failure of both redundant shutdown pumps. This scenario results in no damage to the fuel, showing that natural convection and pool boiling cooling is adequate to provide cooling of the fuel in the shutdown condition, even immediately following a scram due to loss of all primary pumps.

\subsubsection{Operation with Natural Convection}

The analysis in (Cheng, 2004) shows that the NBSR fuel can be cooled from the top for powers up to 1.2 MW with no flow (i.e. the case of complete flow blockage at the bottom of an element. The result shows that power up to $1 \mathrm{MW}$ would be tolerable with no forced flow, even without any natural convection (but boiling would occur).

The RELAP5 code has been used to analyze operation at $100 \mathrm{~kW}$ with natural convection allowed, and shows that safe operation is possible at this power. The peak fuel centerline temperature is about $54 \mathrm{~K}$ below the saturation temperature. The peak heat flux is at least an order of magnitude below the calculated CHF and the wall heat flux corresponding to the OFI condition.

\subsection{References}

Baek, J.S., Cuadra, A., Hanson, A.L., Cheng, L-Y., Brown, N.R., and Diamond, D.J., “Accident Analysis for the NIST Research Reactor Before and After Fuel Conversion - Revision 1,” BNL98524-2012-IR-R1, Brookhaven National Laboratory, Upton, NY, June 25, 2013.

Baek, J-S., “Power distribution in NBSR Core for RELAP5 Safety Analysis,” BNL Technical Report, Brookhaven National Laboratory, Upton, NY, May 25, 2012.

Brown, N.R., Baek, J.S., Hanson, A.L., Cuadra, A., Cheng, L-Y. and Diamond, D.J., “Irradiation Experiment Conceptual Design Parameters for NBSR Fuel Conversion, Rev.1,” BNL-998972013-IR-R1, Brookhaven National Laboratory, Upton, NY, June 5, 2013 a.

Brown, N.R., Hanson, A.L., and Diamond, D.J., "Local Burn-up Effects in the NBSR Fuel Element,” BNL-99145-2013-IR, Brookhaven National Laboratory, Upton, NY, January 23, 2013b.

Brown, N.R., Hanson, A.L., and Diamond, D.J., "Neutron Flux and Energy Spectrum in the NBSR,” memo to files, Brookhaven National Laboratory, Upton, NY, April 27, 2012.

Burkes, D.E., Mickum, G.S. and Wachs, D.M., “Thermophysical Properties of U-10Mo Alloy,” INL/EXT-10-19373, Idaho National Laboratory, Idaho Falls, ID, November 2010. 
Cheng, L-Y., "Heat Conduction in an NBSR Fuel Plate—Effect on Wall Heat Flux," BNL memorandum, Brookhaven National Laboratory, Upton, NY, April 6, 2010.

Cheng, L-Y. et al., "Physics and Safety Analysis for the NIST Research Reactor," BNL-NIST0803, Rev. 1, Brookhaven National Laboratory, Upton, NY, April 2004.

Cuadra, A., and Cheng, L-Y., "Statistical Hot Channel Analysis for the NBSR,” BNL Technical Report, Brookhaven National Laboratory, Upton, NY, May 27, 2011.

Diamond, D.J., Brown, N., Hanson, A.L., Baek, J.S., and Cheng, L-Y., "NBSR Conversion Safety Analysis Report - LEU Equilibrium Core - Chapter 4,” draft report, Brookhaven National Laboratory, Upton, NY, September 4, 2012.

Hanson, A.L., and Diamond, D.J., "Calculation of Kinetics Parameters for the NBSR,” BNL97007-2012, Brookhaven National Laboratory, Upton, NY, March 2012.

Hanson, A.L. and Diamond, D.J., "Calculation of Design Parameters for an Equilibrium LEU Core in the NBSR," Technical Report, Brookhaven National Laboratory, Upton, NY, September 29, 2011a.

Hanson, A., and Diamond, D., "A Neutronics Methodology for the NIST Research Reactor Based on MCNPX," in 19th International Conference on Nuclear Engineering (ICONE19), Chiba, Japan, May 16-19, 2011b.

Hanson, A. and Diamond, D., "Determination of Inventories and Power Distributions for the NBSR,” Proceedings of the TRTR/IGORR Joint Meeting, Gaithersburg, MD, September 12-16, 2005a.

Hanson, A. and Diamond, D., "Energy Deposition in the NBSR,” BNL internal memo, Brookhaven National Laboratory, February 2, 2005b.

Kaminaga, M., Yamamoto, K., and Sudo, Y., "Improvement of Critical Heat Flux Correlation for Research Reactors using Plate-Type Fuel,” J. Nucl. Sci. Technol. 35[12], 943-951, 1998.

Kiedrowski, B. et al., "MCNP5-1.6 Feature Enhancements and Manual Clarifications, LA-UR10-06217," Los Alamos National Laboratory, Los Alamos, NM, 2010.

NBS, "Final Safety Analysis Report on the National Bureau of Standards Reactor,” NBSR 9, The National Bureau of Standards (NBS), Gaithersburg, MD, 1966 and Addendum 1, November 1980 .

NIST, "Safety Analysis Report (SAR) for License Renewal for the National Institute of Standards and Technology Reactor - NBSR; NBSR 14, Rev 4" National Institute of Standards and Technology (NIST), Gaithersburg, MD, 2010a. 
NIST, "Specification for Aluminum Clad Fuel Elements for the National Bureau of Standards Reactor,” NCNR-ACFESpec-01, Rev. 5, National Institute of Standards and Technology (NIST), Gaithersburg, MD, September 3, 2010b.

NIST, “Technical Specifications for the NIST Test Reactor (NBSR),” Appendix A to License No. TR-5, National Institute of Standards and Technology (NIST), Gaithersburg, MD, 2009.

Oh, C.H., and Chapman, J.C., “Two-phase Instability for Low-flow Boiling in Vertical Uniformly Heated Thin Rectangular Channels,” Nuclear Technology, 113, March 1996.

Pelowitz, D.B., "MCNPX User's Manual Version 2.7.0," Los Alamos National Laboratory, Los Alamos, NM, 2011.

Rest, J. et al, “U-Mo Fuels Handbook, Version 1.0," RERTR Program, Argonne National Laboratory, June 2006.

Saha, P., and Zuber, N., "Point of Net Vapor Generation and Vapor Void Fraction in Subcooled Boiling,“ Proc. $5^{\text {th }}$ Int. Heat Transfer Conf., Vol. IV, p. 175, Tokyo, Japan, September 3-7, 1974. 


\section{REACTOR COOLANT SYSTEMS}

It is not expected that there will be any changes the reactor coolant systems of the NBSR as a result of conversion. This chapter will not be needed in the conversion SAR.

\section{ENGINEERED SAFETY FEATURES}

It is not expected that there will be any changes to engineered safety features of the NBSR as a result of conversion. This chapter will not be needed in the conversion SAR.

\section{INSTRUMENTATION AND CONTROL SYSTEMS}

It is not expected that there will be any changes to instrumentation and control systsems of the NBSR as a result of conversion. This chapter will not be needed in the conversion SAR.

\section{ELECTRICAL POWER SYSTEMS}

It is not expected that there will be any changes to electrical power systems of the NBSR as a result of conversion. This chapter will not be needed in the conversion SAR.

\section{AUXILIARY SYSTEMS}

Changes to operational characteristics or in components of the auxiliary systems required by conversion will be discussed in this chapter. This may include fuel handling and storage systems. However, currently there is no information available as to what changes might be necessary.

\section{EXPERIMENTAL FACILITIES AND UTILIZATION}

It is not expected that there will be any changes to experimental facilities of the NBSR as a result of conversion. This chapter will not be needed in the conversion SAR.

\section{RADIATION PROTECTION AND RADIOACTIVE WASTE MANGEMENT PROGRAMS}

Changes to radiation protection and radioactive waste management programs required by conversion will be discussed in this chapter. Currently there is no information available as to what changes might be necessary. In Chapter 4 there will be a discussion of particle flux 
(shielding) calculations to analyze the effectiveness of the concrete biological shield surrounding the core.

\section{CONDUCT OF OPERATIONS}

Various topics related to conduct of operations will be discussed in this chapter. Currently there is no information available as to what if any changes will be necessary except that it is known that a startup plan for the LEU core will have to be developed. 


\section{ACCIDENT ANALYSES}

\subsection{Introduction}

This chapter will present analyses to show that the health and safety of the public and workers are protected in the event of an accident. This protection will result from the facility design features, the Technical Specifications (e.g., Safety Limits, Limiting Safety System Settings (LSSS), and Limiting Conditions for Operation (LCO)), and the well-qualified and trained staff of NCNR. This holistic approach will ensure that no credible accident could lead to unacceptable consequences to people or the environment.

The accident scenarios that need to be considered for the equilibrium core with low enriched uranium (LEU) fuel are identical to those considered in the Safety Analysis Report (SAR) (NIST, 2010a) for the NBSR with high enriched uranium (HEU) fuel. They take into account worst case assumptions expected to lead to the most severe consequences and bound all possible events. The progression of each accident is analyzed to the extent necessary to determine the degree of potential hazard. In addition, the results of the accidents with the LEU fuel are compared to the corresponding results with HEU fuel in order to see how the responses of the NBSR reactor are affected by fuel conversion. In general accidents are analyzed at two points in the fuel cycle: startup (SU, which means at the beginning-of-cycle before equilibrium xenon has built into the core) and end-of-cycle (EOC). The safety limit (see Technical Specifications) for the reactor is the blister temperature for the clad which is $450^{\circ} \mathrm{C}$ for $\mathrm{HEU}$ fuel and expected to be similar for LEU fuel.

A detailed neutronics model used to calculate physics parameters for the HEU- and LEU-fueled cores for use in the accident analysis will be discussed in Chapter 4. The model to be used for the transient analysis in this chapter is used with the RELAP5 code (ISL, 2001). It includes the primary piping from vessel inlet to outlet, primary pump and shut-down pump flow paths, heat exchanger, fuel element geometry and flow area, and flow channels for the six inner and twentyfour outer fuel elements. The initial operating parameters (flows, temperatures, power level and distribution, etc.) are assumed to be at their most limiting values or at the LSSS. The NBSR reactor protection system logic is modeled and initiates a reactor trip, upon reaching a setpoint and after the appropriate instrumentation response delay. Fuel temperature is calculated to assure that no fuel damage, as defined by the blister temperature, can take place. In addition, the critical heat flux ratio (CHFR) and onset of flow instability ratio (OFIR) are evaluated as supplementary parameters to examine integrity of fuel elements. The model differs from that used for the current SAR and will be explained as it is in (Baek, 2013).

\subsection{Maximum Hypothetical Accident}

The maximum hypothetical accident (MHA) scenario for this event will remain the same as in the current SAR. The MHA will be postulated as a complete blockage of flow to one element, leading to complete melting of the fuel plates. Such blockage is very unlikely, but will be assumed for this analysis in order to allow for release of radioactive material. The origin of the blockage will not be identified; it will be simply assumed. 
New analysis will be performed with the source term (including release fractions) to determine off-site dose rates using U-Mo LEU fuel during MHA. This analysis will include the determination of dose due to actinides that were not present in significant quantities in HEU fuel. The results will be compared to results generated in like manner for the current HEU fuel.

\subsection{Accidents Due to Insertion of Excess Reactivity}

\subsubsection{Startup Accident}

The accident scenario for this event will remain the same as in the current SAR. It is assumed to take place during startup of the reactor. The reactor is initially critical at a power level of $100 \mathrm{~W}$. Contrary to operating procedures and all previous training and experience, the operator is then assumed to withdraw the shim arms steadily without any pause, until the reactor is scrammed by a high power level trip. The accident model uses a reactivity insertion rate for the shim arm withdrawal equal to $5 \times 10^{-4} \Delta \mathrm{k} / \mathrm{k} / \mathrm{s}$. This rate is greater than the maximum measured and calculated (as will be shown in Chapter 4) rate at any shim arm initial position. It is, however, the Technical Specification limit on shim arm insertion rate.

The accident will be analyzed using the RELAP5 code at SU and EOC. Details of the calculational model and preliminary results can be found in (Baek, 2013).

\subsubsection{Maximum Reactivity Insertion Accident}

The accident scenario for this event will remain the same as in the current SAR. For this accident a ramp reactivity insertion of $0.005 \Delta \mathrm{k} / \mathrm{k}$ will be assumed to occur in $0.5 \mathrm{~s}$. This amount of reactivity is the Technical Specification limit for the reactivity of any experiment. For conservatism the calculation will not consider any fuel or moderator reactivity feedback.

The accident will be analyzed using the RELAP5 code at SU and EOC. Details of the calculational model and preliminary results can be found in (Baek, 2013).

\subsubsection{Other Reactivity Insertion Events}

It is not credible that excess reactivity can be added to the NBSR by dropping a fuel element into an empty position in a critical core, since there are no empty positions. R efueling is only performed when the reactor is fully shut down with shim safety arms fully inserted. Furthermore, only one element is ever moved at one time, so that an empty position could only arise from an element that had already been removed, making the reactor even more subcritical. When the core is being restored from the storage pool, it is possible to have empty locations in a nearly critical core, but procedural controls are in place to ensure that the shim safety arms are fully inserted when fuel is being moved. Having the shim safety arms inserted would preclude criticality even if the fuel were inserted improperly. No other mechanisms have been identified for a step or fast ramp insertion of reactivity. 


\subsection{Loss of Primary Coolant}

A sudden loss of primary coolant from the NBSR is not credible. The main piping is located in protected areas, system pressures are low, and flow rates are small so that wear is not an issue. Nonetheless, a scenario assumes that a break occurs in the inlet pipe between the reactor inlet valves and the inlet plenums, and coolant drains from the interior of the fuel elements. Coolant exterior to the fuel elements continues to provide some cooling. Another source of cooling is by flow from the inner emergency cooling tank. Nozzles in the distribution pan direct flow from the inner emergency cooling tank to each individual fuel element. This accident is analyzed in the same way as done for the current SAR (NIST, 2010a) and is summarized below.

Assuming heat removal is by boil-off, the makeup flow rate is determined from the decay power calculated by RELAP5 for an initial power of 20.4 MW (allowing for a 2\% uncertainty in core power). Within the first second after shutdown the core makeup flow rate drops below $1 \mathrm{~kg} / \mathrm{s}$. The required makeup flow rate for boil-off is compared to that from the inner emergency cooling tank, calculated as a function of time. The coolant in the fuel element is assumed to have drained out of the break and the tank flow is a result of the hydrostatic head. The flow from the inner emergency cooling tank decreases linearly in time as the water level drops in the tank. For at least 20 minutes after shutdown the tank flow is more than adequate to cool the fuel elements by boil-off. Coolant inventory in the inner emergency cooling tank would be replenished from the 3,000-gallon main emergency cooling tank. Thus there is ample time for the operators to assess the situation and initiate additional emergency cooling as needed.

It takes 30 minutes to completely drain the inner emergency cooling tank under gravity. The required orifice size was calculated analytically (Cheng, 2004) by applying the mechanical energy balance to the water in the tank with an orifice in the bottom. The corresponding initial mass flow rate through the orifice was also calculated analytically. A RELAP5 model of the inner emergency cooling tank was set up and the orifice was modeled as a junction with an abrupt area change. The orifice area was adjusted in the RELAP5 input until the initial orifice flow agreed with the analytical result. Using this orifice area, a RELAP5 calculation was performed to calculate the water level in the emergency tank as a function of time. The results of this calculation were then compared to an analytical solution and showed excellent agreement.

\subsection{Loss of Primary Coolant Flow}

\subsubsection{Loss of Off-Site Power}

The accident scenario for this event will remain the same as in the current SAR. It begins with a loss of off-site power and coastdown of the primary pumps. The reactor trip signal is generated on low primary flow with a $0.4 \mathrm{~s}$ delay. The primary pump discharge valves start closing at $1.0 \mathrm{~s}$ on the primary pump trip signal while the pumps start coastdown from time zero due to the loss of power. One of the two shutdown pumps (SDPs) will be credited in the analysis to remove the decay power. The valves at the outlets of the SDPs are assumed to open. 
The accident will be analyzed using the RELAP5 code at SU and EOC. Details of the calculational model and preliminary results can be found in (Baek, 2013).

\subsubsection{Loss of Both Shutdown Pumps}

In this scenario, the loss of off-site power discussed in Section 13.5.1 above is followed by a complete failure of all backup power sources (a highly unlikely event, as all systems undergo regular surveillance testing). This scenario disables the shutdown pumps to remove the decay power from the core. Since the heat sink (heat exchangers) is located in a lower elevation than the heat source (core), it is expected that after flow coastdown the decay heat is removed by the coolant very slowly moving through the elements and then by boil-off.

The accident will be analyzed using the RELAP5 code at SU and EOC. Details of the calculational model and preliminary results can be found in (Baek, 2013).

\subsubsection{Seizure of One Primary Coolant Pump}

The accident scenario for this event will remain the same as in the current SAR. It is assumed that through some failure, such as a faulty bearing, the rotor of one pump suddenly becomes locked. Because of its momentum, coolant flow through the primary loop will decrease over a finite time interval until a one-third flow reduction is achieved. Since the RELAP5 model lumps all three pumps into one effective pump, the seizure of one of the pumps is modeled by an instantaneous step reduction in the pump speed to two-thirds of full speed. This is conservative since the flow with only two pumps operating would actually be more than two-thirds of full flow. Reactor trip is due to a low-flow signal.

The accident will be analyzed using the RELAP5 code at SU and EOC. Details of the calculational model and preliminary results can be found in (Baek, 2013).

\subsubsection{Throttling of Primary Coolant Flow to the Outer Plenum}

The accident scenario for this event will remain the same as in the current SAR. In this accident scenario, the flow control valve at the inlet to the outer plenum will be assumed to close in $54.5 \mathrm{~s}$ (measured time), reducing the flow through the outer plenum and generating a reactor trip signal $0.4 \mathrm{~s}$ after the flow reaches the low flow trip point of 4,700 gpm (297 l/s). The complete closure of the flow control valve isolates the lower plenum of the outer core and cuts off the supply of forced coolant flow. Since all coolant channels in the fuel elements in the outer core share the same inlet and outlet plenums, closed loop recirculation flow paths are expected to be established between hotter and cooler coolant channels in the outer core. Buoyancy will induce upflow through the hotter coolant channels, while downflow through the cooler channels completes the closed flow loop. It is expected that the recirculation flow removes heat from the fuel elements in the outer core.

The accident will be analyzed using the RELAP5 code at SU and EOC. Details of the calculational model and preliminary results can be found in (Baek, 2013). 


\subsubsection{Throttling of Primary Coolant Flow to the Inner Plenum}

The accident scenario for this event will remain the same as in the current SAR. The flow control valve at the inlet to the inner plenum will be assumed to close, decreasing the flow through the inner plenum and generating a reactor trip signal $0.4 \mathrm{~s}$ after the flow reaches the low flow trip point of 1,200 gpm ( $75.7 \mathrm{l} / \mathrm{s})$. The 8-inch flow control valve has a measured closure time of $28.6 \mathrm{~s}$. The complete closure of the flow control valve isolates the lower plenum of the inner core and at the same time cuts off the supply of forced coolant flow. Since all coolant channels in the fuel elements in the inner core share the same inlet and outlet plenums, closed loop recirculation flow paths are established between hotter and cooler coolant channels in the inner core. Upflow due to buoyancy through the hotter coolant channels and downflow through the cooler channels completes the closed flow loop. Heat from the fuel elements will be removed by the recirculation flow in the inner core.

The accident will be analyzed using the RELAP5 code at SU and EOC. Details of the calculational model and preliminary results can be found in (Baek, 2013).

\subsubsection{Inadvertent Closure of Valve DWV-19}

The accident scenario for this event will remain the same as in the current SAR. Valve DWV19 is a motorized 18-inch butterfly valve, mounted in the outlet line, with a measured stroke time, fully open to fully closed, of $21 \mathrm{~s}$. Although this valve is only used during maintenance when the reactor is shut down, it is conceivable that it could receive a spurious signal while the reactor is operating at full power, resulting in a loss of primary flow. The only cooling mechanisms present after the valve is completely closed are the thermal capacity of the primary coolant in the vessel, and heat transfer from the reactor vessel to the biological shield.

\subsection{Mishandling or Malfunction of Fuel}

The accident scenario for this event will remain the same as in the current SAR. All fuel for the NBSR is subject to stringent quality control to ensure that there will be no "leaky" elements that could release fission products into the primary cooling system. In addition, if any element were to leak, the fission products would be detected immediately, and the faulty element would be identified and removed. This has only happened once in the operating history of the NBSR, and there were no releases to the atmosphere. The releases to the primary coolant were small, and the normal water treatment system quickly removed all traces of activity once the element was removed.

Four separate scenarios involving mishandling of fuel were extensively analyzed in (NBS, 1980), and shown to present no significant risks. These accidents were: a refueling accident involving a dropped element; dropping of a fuel element into the storage pool; dropping of a heavy object onto the fuel rack in the storage pool; and dropping of the spent fuel cask during a shipping operation. There has been no change in any of these accidents so the previous analysis remains valid. 
In addition to the above scenarios, the possibility of an element being inserted into an incorrect position during refueling will also be analyzed to present no possibility of core damage. The analysis of this accident, including showing the acceptability of the results is discussed in (Diamond, 2012).

\subsubsection{Experiment Malfunction}

All experiments associated with the NBSR are carefully reviewed for hazards prior to being approved for construction and installation. Beam experiments external to the biological shield present a very small potential hazard to the reactor. Nevertheless, an experimental proposal must be prepared or amended before they can be installed or significantly modified. All proposals are reviewed in accordance with the Technical Specifications and Administrative Procedures. The Safety Evaluation Committee makes a recommendation to the Director of the NIST Center for Neutron Research, who has responsibility for final approval of any experiment. This includes all experiments involving explosive or corrosive materials. Quantities of explosives to be irradiated in the core are strictly limited to amounts for which any explosion can be totally contained within the experiment packaging.

The only scenario of concern is for an experiment internal to the reactor biological shield. Thus, except for the reactivity issues addressed in Section 13.3.2, experiment malfunctions are not a credible threat to the core. Note too that this accident will also bound flooding of beam tubes.

\subsubsection{Loss of Normal Power}

The bounding scenario of a loss of normal power is due to the resulting loss of flow due to the trip of the coolant pumps. This accident is addressed in Section 13.5.1.

\subsubsection{External Events}

Damage to the core from external events, such as tornados, hurricanes, floods and earthquakes is not considered credible as a result of design features, administrative controls and the seismological and climatological characteristics of the site. Details are provided in (NIST, 2010a).

The NBSR is located in a zone of low seismic activity. The building and reactor systems have been analyzed and shown to be able to withstand the stresses generated by a $0.1 \mathrm{~g}$ earthquake loading (NBS, 1966). The probability of an earthquake resulting in accelerations larger than $0.08 \mathrm{~g}$ is less than $2 \%$ in 50 years.

The confinement building was designed to withstand the forces generated by winds of up to 100 mph, substantially faster than the largest wind ever recorded at Ronald Reagan Washington National Airport (76 mph during passage of Hurricane Hazel, October 1954). 
The computed recurrence interval for a tornado at the NIST site is approximately 2,000 years. The NBSR is immediately shut down if NIST Security notifies the control room that a tornado or other major weather hazard is approaching the site. This action is specified in the Emergency Instructions Manual. Further, if a tornado is sighted on the NIST site, a Notification of Unusual Event is declared.

During unsettled weather conditions, control room personnel monitor all weather alerts. Therefore, none of these scenarios pose a significant threat to the reactor. Furthermore, it is difficult to envision any accident resulting from such a scenario that would have consequences exceeding those discussed in previous sections.

\subsection{Summary and Conclusions}

The analyses given in this chapter show that adherence to the Technical Specifications provide assurance that no reactor accident will lead to fuel damage, except for the MHA, which is postulated to do so. These analyses support the bases for the Technical Specifications as do the thermal-hydraulic limits specified in Chapter 4, which established the LSSS. The Chapter 13 results show that the LSSS determined for routine operation are also adequate to provide assurance that the safety limit will not be exceeded during any credible accident.

This chapter has presented the results of a number of conservative analyses of potential accidents related to operation of the NBSR. No credible accident results in fuel damage. The MHA assumes fuel damage but in that accident the resultant consequences are well within the limits of 10 CFR 100, which applies to Test Reactors (and below 10 CFR 20 limits for the general public). Therefore, operation of the NBSR will present no undue hazard to any member of the general public or to the NCNR staff.

\subsection{References}

Baek, J.S., Cuadra, A., Hanson, A.L., Cheng, L-Y., Brown, N.R., and Diamond, D.J., Accident Analysis for the NIST Research Reactor Before and After Fuel Conversion - Revision 1,” BNL98524-2012-IR-R1, Brookhaven National Laboratory, Upton, NY, June 25, 2013.

Cheng, L., Hanson, A., Diamond, D., Xu, J., Carew, J., and Rorer, D., "Physics and Safety Analysis for the NIST Research Reactor,” BNL-NIST-0803, Rev. 1, Brookhaven National Laboratory, Upton, NY, April 2004.

Diamond, D.J., Brown, N.R., Hanson, A.L., Baek, J.S., and Cheng, L-Y., "NBSR Conversion Safety Analysis Report - LEU Equilibrium Core - Chapter 4,” draft report, Brookhaven National Laboratory, Upton, NY, September 4, 2012.

NBS, “Addendum 1, Final Safety Analysis Report”, National Bureau of Standards (NBS) Research Reactor Radiation Division, Gaithersburg, MD, November 1980. 
NBS, "Supplement B of the Final Safety Analysis Report on the National Bureau of Standards Reactor,” NBSR-9B, National Bureau of Standards (NBS), Gaithersburg, MD, December 1966.

NIST, "Safety Analysis Report (SAR) for License Renewal for the National Institute of Standards and Technology Reactor - NBSR; NBSR 14, Rev 4," National Institute of Standards and Technology (NIST), Gaithersburg, MD, 2010. 


\section{TECHNICAL SPECIFICATIONS}

Changes in the technical specifications that are required by the conversion are introduced in the appropriate chapters and are then repeated in this chapter. Changes that are already known are found in Chapter 4. No others are anticipated at this time.

\section{OTHER LICENSING CONSIDERATIONS}

There are no other licensing considerations currently. It is projected that this chapter will not be needed. 